\section{Methods for improving the prognosis of mechanically ventilated infants with RDS}

Sir,

Manginello et al. (Archives, 1978, 53, 878) stated that in the ventilatory treatment of infants with severe RDS the pressure-limited method of ventilation was better than that of volume-cycled, as with the former, the $\mathrm{FrO}_{2}$ could be reduced more rapidly and complications or death were less common. We obtained similar improvements using volume-cycled ventilation but with a different approach. 1

We studied 56 newborn infants who were given mechanical ventilation for severe RDS between 1973 and 1976. Only the most severely affected infants were intubated and given mechanical ventilation. About half of these babies were apnoeic on admission; the others were ventilated because of progressive and severe deterioration of their clinical status or because of their blood-gases. Arterial $\mathrm{pH}, \mathrm{Po}_{2}$, and $\mathrm{PCO}_{2}$ were the only indications for mechanical ventilation in babies with severe hypercarbia, acidaemia, or in those in whom severe hypoxaemia persisted despite adjustment of continuous distending pressure and $\mathrm{F}_{1} \mathrm{O}_{2}$.

During the years 1973-74 we gave mechanical ventilation to 31 infants with severe RDS and respiratory insufficiency using a volume-cycled ventilator (Bourns LA 104-150) in the controlled mode, with tidal volume of $5 \mathrm{ml} / \mathrm{kg}$, respiratory rate of $60-80 \mathrm{~min}$, positive end expiratory pressure (PEEP) of 3-7 $\mathrm{cmH}_{2} \mathrm{O}$ and $\mathrm{I}: \mathrm{E}$ ratio of $1: 1-1: 2$. Mortality was $74 \%$, pneumothorax or pneumomediastinum, or both, occurred in $23 \%$ of cases, and bronchopulmonary dysplasia was present in $67 \%$ of survivors.

In our attempts to improve the prognosis for mechanically ventilated infants with RDS we noted that, during the acute phase of the disease, if we changed from the controlled to the assisted mode (in which the ventilator cycle is triggered by the patient's inspiratory effort) there was often a significant rise of $\mathrm{PaO}_{2}$. This phenomenon had already been described in infants with RDS ventilated mechanically without PEEP. ${ }^{2}$ Nevertheless Llewellyn and Swyer did not correlate the better oxygenation obtained with this method with changes in the prognosis in their patients. At the beginning of 1975, after we had made this observation, infants were set on a Bourns ventilator (ventilator setting the same as during 1973-74) with $100 \%$ oxygen in controlled respiration as long as arterial pH was $<7.30$ and $\mathrm{PaO}_{2}<50-60 \mathrm{mmHg}(6.6-$ $7.9 \mathrm{kPa})$, and we changed to the assisted mode as soon as $\mathrm{pH}$ and $\mathrm{PaO}_{2}$ attained better values and the patient's respiratory activity was sustained. The patient no longer had to struggle against the ventilator, there was improved oxygenation, and the infant was able to regulate the respiratory rate according to his own needs. With this approach it was possible to lower the $\mathrm{FIO}_{2}$ and to extubate the patient more rapidly. During 1975-76 we ventilated 25 neonates with severe RDS in this way, with a fall in mortality rate to $48 \%$ and with an incidence of pneumothorax or pneumomediastinum, or both, of $8 \%$, while bronchopulmonary dysplasia was found in only $8 \%$ of the survivors. The difference in mortality and bronchopulmonary dysplasia figures in the two study periods was significant $(P<0.05)$. The infants were similar in respect of birthweights, gestational ages, and severity of respiratory disease

We believe that the main advantages of ventilating patients with severe RDS with a volume-cycled ventilator using the assisted (triggered) method are that the baby does not have to struggle against the ventilator, the respiratory rate is automatically regulated, the respiratory centres are continuously activated during the whole ventilation time, and finally, it is quicker and easier to wean the baby from the ventilator.

We suggest that before a final conclusion is made on the superiority of pressure-limited mechanical ventilation in RDS, controlled trials should be done to compare pressure-limited ventilation with other methods of volume-limited ventilation (including the use of PEEP in assisted ventilation with trigger).

\section{References \\ 1 Marzetti G, Marangoni A, Colarizi P, et al. Riduzione della mortalità e degli esiti polmonari dopo introduzione di PEEP in respirazione assistita in neonati $>1200 \mathrm{~g}$ con sindrome respiratoria ventilati meccanicamente. Abstract of paper given at the 39th Congress of the Italian Paedi- atric Society, Venice, 16-19 October, 1978. \\ 2 Llewellyn M A, Swyer P R. Assisted and controlled ventilation in the newborn period: effect on oxygenation. Br J Anaesth 1971; 43: 926-31. \\ G Marzetti, R Agostino, AND C Moretti Newborn Intensive Care Unit, Institute of Paediatrics, University of Rome, Rome, Italy}

\section{Acute infantile thrombocytosis and vitamin $\mathrm{K}$ deficiency associated with intracranial haemorrhage}

Sir,

The paper by Lorber et al. (Archives, 1979, 54, 471) was especially interesting to me because of my observation of thrombocytosis in a 2-month-old infant (to be reported) in whom pronounced vitamin $\mathbf{E}$ and vitamin $\mathbf{D}$ and probable vitamin $K$ and vitamin $A$ deficiency (slightly prolonged prothrombin, partial thromboplastin time, and very low carotene level) were shown. Because other causes of thrombocytosis of infancy were ruled out, infantile hyperostosis was sought and was proved by $x$-ray.

Since thrombocytosis in infancy has been reported in patients with Caffey's disease, ${ }^{1-2}$ possibly related to vitamin $\mathrm{E}$ deficiency, ${ }^{3}$ we suggest that at least a hydrogen peroxide haemolysis test (which was also positive in our case) should be carried out in all patients with infantile thrombocytosis in whom the aetiology is unknown. 